\title{
Efeito Residual e Reaplicação de Boro na Cultura do Eucalipto
}

Residual Effect and Reapplication of Boro in Eucalyptus Culture

Efecto Residual y Reaplicación de Boro en la Cultura del Eucalipto

Thiago de Souza Celestrino Doutorando, UNESP, Campus Ilha Solteira, Brasil thiagocelestrino@yahoo.com.br

Salatiér Buzetti

Professor Doutor, UNESP, Campus Ilha Solteira, Brasil sbuzetti@agr.feis.unesp.br

Fernando Takayuki Nakayama Pesquisador Doutor, APTA-PRDTA Alta Paulista, Brasil fnakayama@apta.sp.gov.br 
RESUMO

É importante verificar se a aplicação de boro (B) realizada inicialmente é suficiente para atender as exigências da cultura ao longo do ciclo, ou se é necessária a reaplicação do elemento em cobertura. Sendo assim, o objetivo do trabalho foi avaliar a altura de planta, o diâmetro a altura do peito (DAP), volume total de madeira com casca de eucalipto, teor de B no solo e concentração deste no folhedo, em função do efeito residual de fontes de B e da aplicação foliar do micronutriente, assim como a reaplicação do elemento em cobertura. $O$ delineamento experimental foi de blocos casualizados, com tratamentos dispostos em esquema fatorial de $3 \times 2 \times 2$ em parcelas subdivididas, sendo: $0 \mathrm{~kg} \mathrm{ha}^{-1}$ de B; $1 \mathrm{~kg} \mathrm{ha}^{-1}$ de B utilizando o fertilizante borogran (baixa solubilidade, $10 \% \mathrm{~B}$ ) e $1 \mathrm{~kg} \mathrm{ha}^{-1}$ de $\mathrm{B}$ utilizando o fertilizante ácido bórico (alta solubilidade, $17 \% \mathrm{~B}$ ), ambos sendo aplicado manualmente em filete contínuo no sulco de plantio. $O$ fatorial 2 se refere à aplicação ou não de $B$ via foliar. A parcela subdividida em 2 se refere às subparcelas que receberam ou não a reaplicação de $B$ aos 34 e 46 meses após o plantio, na dose de $1 \mathrm{~kg} \mathrm{ha}^{-1} \mathrm{de} \mathrm{B}$, cada, utilizando o fertilizante ácido bórico. As reaplicações de B em cobertura propiciaram maiores teores do elemento no solo; logo, houve efeito benéfico para o incremento no DAP e, consequentemente, volume de madeira com casca.

PALAVRAS-CHAVE: Solubilidade, cerrado, micronutriente

\section{ABSTRACT}

It is important to verify if the boron application (B) carried out initially is enough to meet the requirements of the crop over the cycle, or if it is necessary to reapply the element under cover. Therefore, the objective of this work was to evaluate plant height, diameter at breast height $(\mathrm{DBH})$, total volume of wood with eucalyptus bark, B content in the soil and its concentration in the leaf, as a function of the residual effect of B sources and foliar application of the micronutrient, as well as the reapplication of the cover element. The experimental design was randomized blocks, with treatments arranged in a factorial scheme of $3 \times 2 \times 2$ in subdivided plots, being: $0 \mathrm{~kg} \mathrm{ha}^{-1}$ of $\mathrm{B} ; 1 \mathrm{~kg} \mathrm{ha}^{-1}$ of B using borogran fertilizer (low solubility, 10\% B) and $1 \mathrm{~kg} \mathrm{ha}^{-1}$ of B using boric acid fertilizer (high solubility, 17\% B), both being manually applied in continuous fillet in the groove Of planting. Factorial 2 refers to the application or not of $B$ via foliage. The plot subdivided in 2 refers to the subplots that received or not the reapplication of $B$ at 34 and 46 months after planting, at a dose of $1 \mathrm{~kg} \mathrm{ha}^{-1}$ of $B$, each using boric acid fertilizer. The reapplications of $B$ in cover provided higher soil element contents; Therefore, there was a beneficial effect for the increase in DBH and, consequently, volume of bark.

KEY WORDS: Solubility, closed, micronutrient

\section{RESUMEN}

Es importante verificar si la aplicación de boro (B) realizada inicialmente es suficiente para satisfacer las exigencias de la cultura a lo largo del ciclo, o si es necesaria la reaplicación del elemento en cubierta. Por lo tanto, el objetivo del trabajo fue evaluar la altura de planta, el diámetro a la altura del pecho (DAP), volumen total de madera con cáscara de eucalipto, contenido de $B$ en el suelo y concentración de éste en el folleto, en función del efecto residual de Fuentes de B y de la aplicación foliar del micronutriente, así como la reaplicación del elemento en cubierta. El delineamiento experimental fue de bloques casualizados, con tratamientos dispuestos en esquema factorial de $3 \times 2 \times 2$ en parcelas subdivididas, siendo: $0 \mathrm{~kg} \mathrm{ha}^{-1}$ de $\mathrm{B} ; 1 \mathrm{~kg} \mathrm{ha}^{-1}$ de $\mathrm{B}$ utilizando el fertilizante borogran (baja solubilidad, $10 \%$ B) y $1 \mathrm{~kg} \mathrm{ha}^{-1}$ de B utilizando el fertilizante ácido bórico (alta solubilidad, 17\% B), ambos siendo aplicado manualmente en filete continuo en el surco De plantación. El factorial 2 se refiere a la aplicación o no de $B$ vía foliar. La parte subdividida en 2 se refiere a las subparcelas que recibieron o no la reaplicación de B a los 34 y 46 meses después de la siembra, a la dosis de $1 \mathrm{~kg} \mathrm{ha}^{-1}$ de $\mathrm{B}$, cada una, utilizando el fertilizante ácido bórico. Las reaplaciones de $B$ en cubierta propiciaron mayores contenidos del elemento en el suelo; $Y$ luego hubo un efecto benéfico para el incremento en el DAP y, consecuentemente, volumen de madera con cáscara.

PALABRAS CLAVE: Solubilidad, cerrado, micronutriente 


\section{INTRODUÇÃO}

É cada vez mais comum áreas destinadas à plantação de eucalipto abrangendo regiões além daquelas consideradas tradicionais. Nota-se que essa horizontalização de produção florestal está inserindo áreas do bioma Cerrado cujas características são: predomínio de acentuada restrição nutricional, altos teores de alumínio e baixa disponibilidade hídrica. Tais condições limitam o desenvolvimento de raízes e, consequentemente, reduz o volume de solo explorado. Diante disso, a utilização de corretivos e fertilizantes se torna prática obrigatória em operações silviculturais, para que não comprometa a produtividade e inviabilize a sustentabilidade da cultura ao longo dos anos.

Quanto ao manejo florestal, práticas como correção e fertilização têm se destacado em pesquisas, visto o elevado número de trabalhos com respostas positivas a tais operações. No entanto, de acordo com Silva (2011), a recomendação de adubação na literatura precisa ser reavaliada, pois, com a inserção de materiais genéticos mais produtivos, destaque para os clones, possivelmente os tornam mais exigentes que os utilizados para gerar a recomendação atual. Segundo Gazola (2014), as quantidades recomendadas estão bem aquém das utilizadas atualmente pelas empresas florestais.

Notou-se que a maioria das pesquisas a respeito de adubação em essências florestais voltou-se principalmente aos fertilizantes primários (nitrogênio $(N)$, fósforo $(P)$ e potássio $(K)$ ), o que resultou em carência de pesquisas acerca dos micronutrientes e, possivelmente, propiciou maior frequência de sintomas de deficiências destes elementos que, embora sejam requeridos em menores quantidades quando comparados aos macronutrientes, desempenham funções primordiais para o desenvolvimento da cultura.

Segundo Pinheiro (1999) e Bouchardet (2002), em áreas do bioma Cerrado, boro (B), cobre $(\mathrm{Cu})$ e zinco $(\mathrm{Zn})$ são os micronutrientes que merecem devida atenção, em virtude da maior ocorrência de sintomas de deficiências em áreas comerciais. Sgarbi et al. (1999) constataram que a deficiência de $B$ é uma das mais limitantes para o crescimento da cultura na fase jovem (até dois anos de idade), resultando em morte do ápice dos ramos e superbrotação lateral, condições essas que afetam a qualidade da madeira e a colheita em sistemas mecanizados. Segundo Althoff et al. (1991), a intensidade dos sintomas varia com a duração do período seco, espécie e fase de crescimento da cultura.

Embora a função do B no metabolismo vegetal ainda não seja totalmente clara, há evidências que o elemento apresenta funções no alongamento celular, síntese de ácidos nucleicos, respostas hormonais, funcionamento de membranas e regulação do ciclo celular (BROWN et al., 2002). Assim, a importância do B em plantios florestais está associado à qualidade da madeira, pois atua no crescimento meristemático e na formação da parede celular, mais especificamente na síntese de pectina, lignina e celulose (MARSCHNER, 1995).

A aplicação de micronutrientes via solo tem como objetivo aumentar a concentração do elemento na solução do solo, que é onde as raízes os absorvem. Sendo assim, para evitar possíveis perdas, é necessário que as fontes de micronutrientes utilizadas se solubilizem no 
solo, no mínimo, em velocidade compatível com a absorção pelas raízes (LOPES, 1991; VOLKWEISS, 1991).

A escolha da fonte de B a ser aplicada depende de alguns fatores, a exemplo, do tipo de solo, cultura e disponibilidade hídrica. Os adubos boratados, em sua grande maioria, apresenta alta solubilidade, favorecendo a sua mobilidade no solo e, possivelmente, a lixiviação do elemento, principalmente em solos arenosos. Diante disso, tem-se optado pela utilização de fontes menos solúveis, o que propicia menores perdas do elemento (MORTVEDT, 1994).

Assim como as raízes, as folhas das plantas tem capacidade de absorver os nutrientes depositados na forma de solução em sua superfície. Diante disso, surgiu a prática da adubação foliar em que soluções de um ou mais nutrientes são pulverizadas sobre a parte aérea das plantas, atingindo principalmente as folhas (VOLKWEISS, 1991). Entretanto, tal prática não deve ser adotada como técnica principal para o fornecimento de nutrientes (VALERI; CORRADINI, 2000; MENEGASSI, 2012). Para o B, em virtude da imobilidade no floema em algumas espécies, é discutível sua aplicação nas folhas (FAQUIN, 2005). As informações a respeito da fertilização foliar florestal são escassas e, em termos do eucalipto, serão necessários mais estudos que comprovem sua eficiência (DAHMARDEH; MEHRAVARAN, NADERI, 2011).

\section{OBJETIVO}

Em solos de Cerrado, que apresentam baixo teor de matéria orgânica (M.O), sendo esta a principal fonte primária de $B$, é comum a adubação no sulco de plantio e via foliar na fase de implantação da cultura. Portanto, é importante verificar se a aplicação de B realizada inicialmente é suficiente para atender as exigências da cultura ao longo do ciclo, ou se é necessária a reaplicação do elemento em cobertura. Sendo assim, o objetivo do trabalho é comparar, aos 48 meses após o plantio, o efeito residual das fontes de B no sulco de plantio, bem como da aplicação foliar do elemento, e a reaplicação de B em cobertura, na cultura do eucalipto (clone I144 - E. urograndis).

As avaliações realizadas foram: a) altura de plantas; b) diâmetro à altura do peito (DAP); c) volume de madeira com casca; d) teor de boro no solo e e) concentração de boro no folhedo.

\section{METODOLOGIA}

O experimento foi implantado em janeiro de 2012, localizado na Fazenda Renascença, fundo agrícola administrado pela Cargill Agrícola, no município de Três Lagoas, MS, com latitude $20^{\circ}$ $34^{\prime} \mathrm{S}$ e longitude $51^{\circ} 50^{\prime} \mathrm{O}$ e altitude de aproximadamente $305 \mathrm{~m}$. Essa área experimental era ocupada por pastagem degradada, cultivada com Urochloa brizantha (Syn. Brachiaria) há 20 anos.

A classificação climática da região de acordo com Köppen é Aw, definido como tropical úmido com estação chuvosa no verão e seca no inverno.

O solo é classificado como Neossolo Quartzarênico Órtico, segundo o sistema brasileiro de classificação de solos (SANTOS et al., 2013). Essa classe de solo tem como característica a grande quantidade de fração areia ao longo do perfil, sendo verificado na Tabela 1. 
Tabela 1: Análise granulométrica do solo da área experimental. Três Lagoas/MS, 2011.

\begin{tabular}{cccc}
\hline $\begin{array}{c}\text { Profundidades } \\
(\mathbf{c m})\end{array}$ & Argila & Silte & Areia Total \\
\cline { 2 - 4 } $0-20$ & 85 & $\mathrm{~g} \mathrm{~kg}^{-1}$ & 898 \\
$20-40$ & 104 & 17 & 876 \\
$40-60$ & 114 & 20 & 869 \\
$60-80$ & 121 & 17 & 861 \\
$80-100$ & 130 & 18 & 849 \\
$100-120$ & 145 & 21 & 831 \\
\hline
\end{tabular}

Fonte: CELESTRINO, 2011.

As características químicas do solo foram determinadas antes da instalação do experimento (Setembro/2011), segundo metodologia proposta por Raij et al. (2001), sendo as amostragens realizadas nas camadas de 0 a 20 e 20 a $40 \mathrm{~cm}$. 0 solo, de forma geral, apresentou baixos teores de M.O e nutrientes. De acordo com os limites de interpretação dos teores dos nutrientes proposto por Raij et al. (1997), o teor de B neste solo é tido como médio (0,21 $0,6 \mathrm{mg} \mathrm{dm}^{-3} \mathrm{de} \mathrm{B}$ ) na camada superficial (0 a $20 \mathrm{~cm}$ ) (Tabela 2).

Tabela 2: Caracterização química inicial da área experimental. Três Lagoas/MS, 2011.

\begin{tabular}{|c|c|c|c|c|c|c|c|c|c|}
\hline Prof. & $\mathbf{P}_{\text {resina }}$ & MO & $\mathrm{pH}$ & $\mathbf{K}$ & $\mathrm{Ca}$ & Mg & $\mathrm{H}+\mathrm{Al}$ & Al & SB \\
\hline$(\mathrm{cm})$ & $\mathrm{mg} \mathrm{dm}^{-3}$ & $\mathrm{~g} \mathrm{dm}^{-3}$ & $\mathrm{CaCl}_{2}$ & \multicolumn{6}{|c|}{$\mathrm{mmol}_{\mathrm{c}} \mathrm{dm}^{-3}$} \\
\hline $0-20$ & 1 & 7,4 & 4,2 & 0,2 & 4,2 & 1,9 & 17 & 4,3 & 6,3 \\
\hline $20-40$ & 1 & 6,8 & 4,2 & 0,3 & 1,6 & 1,1 & 18 & 4,5 & 3,0 \\
\hline Prof. & CTC & $\mathbf{V}$ & $m$ & $\mathrm{~S}^{-\mathrm{SO}_{4}}{ }^{2-}$ & B & $\mathrm{Cu}$ & $\mathrm{Zn}$ & $\mathrm{Mn}$ & $\mathrm{Fe}$ \\
\hline$(\mathrm{cm})$ & $\mathrm{mmol}_{\mathrm{c}} \mathrm{dm}^{-3}$ & \multicolumn{2}{|c|}{$\%$} & \multicolumn{6}{|c|}{$\mathrm{mg} \mathrm{dm}^{-3}$} \\
\hline $0-20$ & 23,3 & 27 & 25 & 4,7 & 0,27 & 0,4 & 0,2 & 1,5 & 13 \\
\hline $20-40$ & 21,0 & 14 & 25 & 4,0 & 0,20 & 0,5 & 0,2 & 1,4 & 20 \\
\hline
\end{tabular}

O método de extração usado para os micronutrientes catiônicos foi o DTPA, para o boro foi a água quente Fonte: CELESTRINO, 2011.

Sendo uma área de pastagem degradada, foram necessárias algumas atividades para que posteriormente houvesse a implantação da cultura do eucalipto. Em setembro de 2011 iniciaram-se as atividades silviculturais: a) controle inicial das formigas cortadeiras, com aplicação de isca formicida granulada (1,5 $\mathrm{g} \mathrm{ha}^{-1}$ do ingrediente ativo (i.a.) sulfluramida); b) calagem, com aplicação de $1500 \mathrm{~kg} \mathrm{ha}^{-1}$ de calcário de PRNT 80\% a lanço em área total; c) gessagem, com aplicação de $500 \mathrm{~kg} \mathrm{ha}^{-1}$ de gesso a lanço em área total; d) controle de pré-plantio das formigas cortadeiras, em duas 2 etapas: 5 a 7 de dezembro de 2011 e 2 a 4 de janeiro de 2012, com aplicação de isca formicida granulada $\left(0,9\right.$ e $0,6 \mathrm{~g}^{-1}$ do i.a. sulfluramida, respectivamente); e) controle químico de plantas daninhas em área total (dessecação), 20 de janeiro de 2012, sendo aplicados $2880 \mathrm{~g} \mathrm{ha}^{-1}$ do i.a. do glyphosate; f) preparo do solo: janeiro de 2012, subsolagem na linha de plantio, com utilização de subsolador, até a profundidade média de $45 \mathrm{~cm}$; g) plantio das mudas e demarcação das parcelas experimentais: realizada em 28 janeiro de 2012, utilizando mudas do clone 1144 (Eucalyptus urophylla x Eucalyptus grandis); h) fertilização de plantio: realizada em 29 de janeiro de 2012, sendo aplicado o fertilizante de forma manual, em filete contínuo, no sulco de plantio. A dose utilizada na adubação de plantio foi $150 \mathrm{~kg} \mathrm{ha}^{-1}$ da fórmula 10-27-10 associada a $30 \mathrm{~kg} \mathrm{ha}^{-1}$ de $\mathrm{P}_{2} \mathrm{O}_{5}$ proveniente do superfosfato triplo $\left(45 \% \mathrm{P}_{2} \mathrm{O}_{5}\right)$, sendo esta recomendação 
baseada na fertilidade de solo, seguindo os critérios utilizados pela empresa para plantios comerciais. Também foram realizadas no plantio as adubações de $\mathrm{Cu}$ e $\mathrm{Zn}$, na dose de $1 \mathrm{~kg} \mathrm{ha}^{-1}$, utilizando os fertilizantes sulfato de cobre e sulfato de zinco, respectivamente; i) irrigação manual das mudas: 28 a 31 de janeiro; j) replantio das mudas mortas: em 20 de fevereiro de 2012 e k) irrigação: 20 a 23 de fevereiro de 2012.

Em março de 2012 (2 meses após o plantio), foi realizada a primeira fertilização nitrogenada e potássica de cobertura, sendo-os aplicados manualmente na entre linha (projeção da copa), distribuídos em meia-lua na parte superior da linha de plantio. Na adubação nitrogenada utilizou-se nitrato de amônio na dose de $40 \mathrm{~kg} \mathrm{ha}^{-1}$ de $\mathrm{N} \mathrm{e}$, na potássica foi utilizado o cloreto de potássio na dose de $50 \mathrm{~kg} \mathrm{ha}^{-1}$ de $\mathrm{K}_{2} \mathrm{O}$.

Para manutenção do experimento, foram realizadas outras atividades: a) controle químico das plantas daninhas na entre linha: 12 de março e 5 de novembro de 2012, foram aplicados 2880 $\mathrm{g} \mathrm{ha}^{-1}$ do i.a. do glyphosate; b) controle químico das plantas daninhas na linha: 9 de maio de 2012, com aplicação de herbicida pré-emergente, sendo usado $0,14 \mathrm{~g} \mathrm{ha}^{-1}$ do i.a. isoxaflutol; c) controle de manutenção das formigas cortadeiras: 4 de junho e 7 de setembro de 2012, com aplicação de isca formicida granulada $\left(0,3\right.$ e $1,5 \mathrm{~g} \mathrm{ha}^{-1}$ do i.a. de sulfluramida, respectivamente) e d) segunda fertilização de cobertura: Em outubro de 2012 (9 meses após o plantio), sendo utilizado nitrato de amônio na dose de $40 \mathrm{~kg} \mathrm{ha}^{-1}$ de $\mathrm{N}$ e cloreto de potássio na dose de $50 \mathrm{~kg} \mathrm{ha}^{-1}$ de $\mathrm{K}_{2} \mathrm{O}$.

As atividades de manutenção do ano de 2013 foram: a) controle químico das plantas daninhas na entre linha: 22 de janeiro e 5 de novembro de 2013, foram aplicados $2880 \mathrm{~g}^{-1} \mathrm{a}^{-1}$ do i.a. do glyphosate; b) terceira fertilização de cobertura: 30 de março de 2013 (14 meses após o plantio), sendo utilizado nitrato de amônio na dose de $40 \mathrm{~kg} \mathrm{ha}^{-1}$ de $\mathrm{N}$ e cloreto de potássio na dose de $50 \mathrm{~kg} \mathrm{ha}^{-1}$ de $\mathrm{K}_{2} \mathrm{O}$; c) controle de manutenção das formigas cortadeiras: 22 de maio e 1 de julho de 2013, com aplicação de isca formicida granulada (0,3 e 1,5 $\mathrm{g} \mathrm{ha}^{-1}$ do i.a. da sulfluramida, respectivamente); d) roçada manual: 17 de novembro de 2013.

As atividades de manutenção dos anos de 2014, 2015 e 2016 foram: a) controle de manutenção das formigas cortadeiras: maio e julho de 2014, 2015 e 2016 com aplicação de isca formicida granulada (0,3 e 1,5 $\mathrm{g} \mathrm{ha}^{-1}$ do i.a. da sulfluramida, respectivamente).

A implantação do experimento foi em janeiro de 2012, sendo utilizado delineamento experimental de blocos casualizados, onde os tratamentos foram dispostos em esquema fatorial e em parcelas subdivididas, com cinco repetições. Cada subparcela foi composta por 24 plantas, distribuídas em três linhas de oito plantas cada, no espaçamento de 3,0 x 2,5 m. A área útil das subparcelas foi composta por 18 árvores, excluindo-se uma árvore de cada extremidade das linhas, sendo estas consideradas bordaduras.

Os tratamentos dispostos em um esquema fatorial já implantado com as fontes de B aplicadas no sulco de plantio e a aplicação ou não de B via foliar, foram subdivididos com a reaplicação ou não deste elemento em cobertura, se tornando um esquema fatorial e em parcelas subdivididas de $3 \times 2 \times 2$, sendo: $0 \mathrm{~kg} \mathrm{ha}^{-1}$ de $\mathrm{B} ; 1 \mathrm{~kg} \mathrm{ha}^{-1}$ de $\mathrm{B}$ utilizando o fertilizante borogran (baixa solubilidade, $10 \% \mathrm{~B}$ ), aplicado manualmente em filete contínuo no sulco de plantio; $1 \mathrm{~kg} \mathrm{ha}^{-1}$ de B utilizando o fertilizante ácido bórico (alta solubilidade, 17\% B), sendo aplicado manualmente em filete contínuo no sulco de plantio. $O$ fatorial 2 se refere à aplicação ou não 
de $B$ via foliar. Foram realizadas duas aplicações foliares de B, aos quatro e dez meses após o plantio. Em cada aplicação, foi utilizado ácido bórico a $0,5 \%$ na calda com volume de $250 \mathrm{~L} \mathrm{ha}{ }^{-1}$, sendo essas aplicações realizadas no período da manhã, com o auxílio de uma bomba costal. Com a finalidade de aumentar o contato com a folha, reduzir deriva e retardar a evaporação da gota foi adicionado óleo mineral (0,2\%). A parcela subdividida em 2 , se refere às subparcelas que recebeu ou não a reaplicação de $B$ aos 34 e 46 meses após o plantio, sendo aplicado manualmente na projeção da copa, distribuídos em meia-lua na parte superior da linha de plantio a distância de $50 \mathrm{~cm}$ da planta. Para cada aplicação foi utilizado o fertilizante ácido bórico na dose de $1 \mathrm{~kg} \mathrm{ha}^{-1} \mathrm{de}$ B. Os tratamentos estão exemplificados na Tabela 3.

Tabela 3: Tratamentos no esquema fatorial 3 × $2 \mathrm{em}$ parcelas subdivididas (2).

\begin{tabular}{cccc}
\hline \multirow{2}{*}{ Tratamentos } & \multicolumn{3}{c}{ Modo de aplicação } \\
\cline { 2 - 4 } & Solo & Foliar & Reaplicação \\
\cline { 2 - 4 } T1 & - & - & \\
T3 & Borogran & - & \\
T4 & Ácido Bórico & - & \\
T5 & Borogran & Ácido Bórico & \\
T6 & Ácido Bórico & Ácido Bórico & \\
T7 & - & Ácido Bórico & \\
T8 & - & - & Ácido Bórico \\
T9 & Borogran & - & Ácido Bórico \\
T10 & Ácido Bórico & - & Ácido Bórico \\
T11 & Borogran & Ácido Bórico & Ácido Bórico \\
T12 & Ácido Bórico & Ácido Bórico & Ácido Bórico \\
\end{tabular}

Fonte: CELESTRINO, 2014

Aos 48 meses do plantio foram avaliadas todas as plantas da parcela, sendo determinado: a) altura total de planta, com o auxílio do aparelho Forestor Vertex, composto por um hipsômetro e um emissor (transponder); b) diâmetro à altura do peito (DAP), determinado a $1,30 \mathrm{~m}$ de altura do solo e c) volume total de madeira com casca, sendo estimado pelas seguintes equações:

$$
\begin{aligned}
& V_{t c}=\Sigma V_{i} / A_{i} * 10000 \\
& V_{i}=\pi^{*}\left(D A P_{i}\right)^{2 * f f * H / 4}
\end{aligned}
$$

(equação 1)

(equação 2)

Onde: $V_{i}=$ volume de madeira com casca da árvore $A_{i}=$ área da subparcela útil $\left(135 \mathrm{~m}^{2}\right)$; $\mathrm{V}_{\mathrm{tc}}=$ volume total com casca $\left(\mathrm{m}^{3} \mathrm{ha}^{-1}\right) ; \mathrm{DAP}_{\mathrm{i}}=$ diâmetro à altura do peito de cada árvore $(\mathrm{m})$; $\mathrm{ff}=$ fator de forma. Neste caso, devido à inexistência de fatores definidos regionalmente para $\mathrm{o}$ clone em estudo, foi atribuído o valor 0,5 e $\mathrm{H}_{\mathrm{i}}=$ altura total de cada árvore (m).

Foi realizada aos 48 meses após o plantio do eucalipto a coleta de solo da área experimental, com o auxílio do trado tipo caneca. Foram coletadas amostras de solo tanto na linha como na entrelinha do plantio (aproximadamente $50 \mathrm{~cm}$ da planta), sendo coletadas cinco amostras por parcela nas camadas de 0 a $20 \mathrm{~cm}$ e 20 a $40 \mathrm{~cm}$; essas amostras foram encaminhadas para a estufa e, após a secagem, foram peneiradas em malha de $2 \mathrm{~mm}$ e assim encaminhadas ao Laboratório de fertilidade do solo UNESP/ Ilha Solteira para realização da análise química dos macro e micronutrientes de acordo com a metodologia descrita por Raij et al. (2001). 
Para quantificar a concentração de B presente no folhedo, foram utilizados coletores com molduras de madeira $(50 \times 50 \mathrm{~cm}$ ) que prendem uma tela de nylon (tipo sombrite) fixada sobre quatro piquetes de madeira e suspensa a aproximadamente $30 \mathrm{~cm}$ acima do solo. Cada subparcela foi constituída por 2 coletores. Os coletores foram instalados aos 30 meses de idade do eucalipto. Foram realizadas três repetições, totalizando 72 coletores. As amostras do folhedo após a secagem foram pesadas e encaminhadas ao laboratório de Nutrição de Plantas UNESP/Ilha Solteira para se efetuar a análise química do elemento.

Os resultados foram analisados através de análise de variância e teste de Tukey $5 \%$ de probabilidade para comparação de médias das fontes e modos de aplicação, assim como a reaplicação do elemento, utilizando-se do programa SISVAR (Ferreira, 2008).

\section{RESULTADOS}

O efeito residual das fontes de B aplicadas no plantio, assim como as aplicações de B via foliar, não influenciaram as mensurações de altura de plantas, DAP e volume de madeira com casca, aos 48 meses após o plantio. Contudo, observou-se que a reaplicação de B, aos 34 e 46 meses após o plantio, na dose de $1 \mathrm{~kg} \mathrm{ha}^{-1}$ de $\mathrm{B}$, cada, em cobertura, utilizando o fertilizante ácido bórico, proporcionou incremento no DAP; logo, propiciou o aumento do volume de madeira com casca (Tabela 4).

Oliveira, Moraes e Buzetti (2001), estudando o efeito da adubação NPK com a presença e omissão de B em Eucalyptus citriodora, verificaram que em solo com teor médio do elemento, realizando duas aplicações de $B$, na dose de $1 \mathrm{~kg} \mathrm{ha}^{-1}$ de $B$ cada, somente propiciou maior crescimento em altura de plantas aos 7 anos de idade.

Ramos et al. (2009), estudando em casa de vegetação doses de $B(0,0 ; 0,25 ; 0,75 ; 2,25$; $6,25 \mathrm{mg} \mathrm{kg}^{-1}$ ) no $E$. citriodora, constataram que até os 140 dias após o plantio não se obteve resposta significativa em função das doses de $\mathrm{B}$, mesmo o solo apresentando teor baixo do elemento. Dessa forma, segundo os autores, a altura de plantas possivelmente não seria um bom parâmetro para avaliar a resposta do eucalipto à aplicação de B. De encontro a esses resultados, Maffeis, Silveira e Brito (2000) constataram que a não aplicação de B reduziu significativamente o crescimento em altura de Eucalyptus citriodora.

Tabela 4: Valores médios de DAP, altura e volume de madeira com casca do eucalipto em função dos tratamentos com boro. Três Lagoas/MS, 2016.

\begin{tabular}{cccc}
\hline \multirow{2}{*}{ Tratamentos } & DAP & Altura & Volume \\
\cline { 2 - 4 } & $\mathrm{cm}$ & $\mathrm{m}$ & $\mathrm{m}^{3} \mathrm{ha}^{-1}$ \\
\hline Plantio & & & \\
Testemunha & $13,92 \mathrm{a}$ & $20,20 \mathrm{a}$ & $207,5 \mathrm{a}$ \\
Acido Bórico & $13,61 \mathrm{a}$ & $20,09 \mathrm{a}$ & $198,2 \mathrm{a}$ \\
Borogran & $13,92 \mathrm{a}$ & $20,37 \mathrm{a}$ & $210,7 \mathrm{a}$ \\
\hline D.M.S. (5\%) & 1,20 & 1,22 & 42,8 \\
\hline Foliar & & & \\
sem & $14,14 \mathrm{a}$ & $20,42 \mathrm{a}$ & $217,1 \mathrm{a}$ \\
com & $13,49 \mathrm{a}$ & $20,02 \mathrm{a}$ & $193,8 \mathrm{a}$ \\
\hline D.M.S. (5\%) & 0,81 & 0,82 & 28,8 \\
\hline Reaplicação & & & \\
sem & $13,38 \mathrm{~b}$ & $19,88 \mathrm{a}$ & $190,8 \mathrm{~b}$ \\
com & $14,24 \mathrm{a}$ & $20,56 \mathrm{a}$ & $220,1 \mathrm{a}$ \\
\hline D.M.S. (5\%) & 0,81 & 0,82 & 28,8 \\
\hline C.V. (5\%) & 8,45 & 5,86 & 20,32 \\
\hline
\end{tabular}

Médias seguidas de mesma letra na coluna não diferem pelo teste de Tukey, a $5 \%$ de probabilidade. Fonte: CELESTRINO, 2016 
Segundo Gonçalves e Valeri (2001), respostas à aplicação de B têm sido constatadas nas diversas regiões do Brasil, principalmente em áreas com déficit hídrico e solos de textura arenosa, cuja disponibilidade do elemento é reduzida. No presente estudo, mesmo o solo apresentando textura arenosa e baixo teor de M.O, não houve resposta ao efeito residual da aplicação de $B$ no plantio. Todavia, ficou caracterizado o efeito benéfico das reaplicações de $B$ em cobertura, na dose de $1 \mathrm{~kg} \mathrm{ha}^{-1}$ de $B$ cada, nas mensurações do DAP e volume de madeira com casca aos 48 meses após o plantio. As respostas às adubações com $B$ têm sido conflitantes e, a exemplo, Tirloni et al. (2011) observaram que aplicações de B, tanto no início do período de estiagem como no período das águas, não influenciaram significativamente o DAP de Corymbia citriodora até os 29 meses de idade.

Paula (2009) verificou em solo de teor médio de $B$, que as fontes de $B$ utilizadas em seu estudo não promoveram diferença significativa para a mensuração do DAP até os 20 meses de idade. No presente trabalho, era de se esperar que, em função do longo ciclo da cultura, a adubação boratada utilizando fontes de baixa solubilidade (borogran), disponibilizaria o elemento mais lentamente, o que, por conseguinte, favoreceria a absorção do elemento, resultando em efeito benéfico para a cultura. Entretanto, não ficou caracterizada diferença entre as fontes de B utilizadas no plantio, visto que ambas se comportaram de maneira similar em relação aos atributos avaliados até os 48 meses após plantio.

No presente estudo, o efeito residual da aplicação de $1 \mathrm{~kg}^{\text {ha }}{ }^{-1}$ de $B$ no plantio, não foi suficiente para promover incremento no DAP aos 48 meses de idade. Tal fato, associado à resposta positiva com a reaplicação do elemento em cobertura, é um indicativo de que o clone em estudo seja mais exigente em termos de adubação boratada, e assim, necessite de doses maiores do que a aplicada no plantio, para que expresse seu potencial genético.

Nota-se que em solos de baixa fertilidade, a adubação boratada é feita em conjunto com os macronutrientes ( $\mathrm{N}, \mathrm{P}$ e K), sendo parcelada durante a implantação do eucalipto (24 meses de idade). Resultados positivos têm demonstrado a necessidade de tal aplicação para ganhos em produtividade, interferindo no volume de madeira e crescimento em diâmetro (FONSECA; MALUF; OLIVEIRA, 1990; GIOVANETTI, 1999). No presente trabalho, mesmo a reaplicação de B, aos 34 e 46 meses após o plantio, sendo estas consideradas tardias, foram benéficas para a cultura, pois resultou em maior DAP e volume de madeira com casca.

Aos 48 meses após o plantio, notou-se que o fertilizante de menor solubilidade (borogran) proporcionou maior efeito residual do elemento no solo quando comparado ao ácido bórico na linha de plantio, camada de 0,0 a 20,0 cm. Era mesmo de se esperar que este fertilizante, em virtude da liberação gradativa do elemento, proporcionasse maiores teores de B no solo (Tabela 5). 
Tabela 5: Teores de boro no solo na linha e na entre linha de plantio do eucalipto, nas profundidades de 0-20 e 20-40 cm após 48 meses do plantio, em função dos tratamentos com boro. Três Lagoas/MS, 2016.

\begin{tabular}{|c|c|c|c|c|}
\hline \multirow{3}{*}{ Tratamentos } & \multicolumn{4}{|c|}{ Teor de B $\left(\mathrm{mg} \mathrm{dm}^{-3}\right)$} \\
\hline & \multicolumn{2}{|c|}{ Linha } & \multicolumn{2}{|c|}{ Entre Linha } \\
\hline & $0,0-20,0 \mathrm{~cm}$ & $20,0-40,0 \mathrm{~cm}$ & $0,0-20,0 \mathrm{~cm}$ & $20,0-40,0 \mathrm{~cm}$ \\
\hline \multicolumn{5}{|l|}{ Plantio } \\
\hline Testemunha & $0,18 b$ & $0,19 a$ & $0,21 \mathrm{a}$ & 0,15 a \\
\hline Acido Bórico & $0,19 b$ & 0,27 a & $0,42 \mathrm{a}$ & $0,36 \mathrm{a}$ \\
\hline Borogran & $0,23 a$ & $0,25 a$ & $0,40 a$ & $0,40 a$ \\
\hline D.M.S. (5\%) & 0,04 & 0,09 & 0,21 & 0,29 \\
\hline \multicolumn{5}{|l|}{ Foliar } \\
\hline Sem & $0,21 \mathrm{a}$ & 0,24 a & 0,35 a & 0,34 a \\
\hline Com & $0,19 a$ & $0,23 \mathrm{a}$ & $0,33 a$ & $0,27 \mathrm{a}$ \\
\hline D.M.S. (5\%) & 0,03 & 0,06 & 0,14 & 0,20 \\
\hline \multicolumn{5}{|l|}{ Reaplicação } \\
\hline Sem & 0,19 a & $0,25 \mathrm{a}$ & $0,19 \mathrm{~b}$ & $0,14 \mathrm{~b}$ \\
\hline Com & $0,21 a$ & $0,23 a$ & $0,50 a$ & $0,47 a$ \\
\hline D.M.S. $(5 \%)$ & 0,03 & 0,06 & 0,14 & 0,20 \\
\hline C.V. (5\%) & 19,53 & 5,71 & 10,70 & 14,60 \\
\hline
\end{tabular}

Médias seguidas de mesma letra na coluna não diferem pelo teste de Tukey, a 5\% de probabilidade.

Fonte: CELESTRINO, 2016

Verificou-se na linha de plantio, na camada de 0,0 a 20,0 cm que, de acordo com o limite de interpretação dos teores deste elemento proposto por Raij et al. (1997), somente o efeito residual do fertilizante borogran, aplicado no sulco de plantio, foi suficiente para obter teores de $\mathrm{B}$ tidos como médio $\left(0,21-0,6 \mathrm{mg} \mathrm{dm}^{-3} \mathrm{de} \mathrm{B}\right)$; logo, os tratamentos submetidos à aplicação de ácido bórico atingiu valores similares ao tratamento testemunha, tidos como teores baixos para a cultura. A possível explicação seria que o ácido bórico (alta solubilidade), presente na forma molecular e não iônica, favoreceu o caminhamento em profundidade, visto maiores teores do elemento na camada de 20,0 a $40,0 \mathrm{~cm}$. Sendo assim, embora seja possível que o B proveniente do ácido bórico tenha sido lixiviado, este efeito não prejudicou o desenvolvimento da cultura, pois a estimativa do volume de madeira aos 48 meses após o plantio foi semelhante, independente da fonte de B.

Celestrino (2014), após 24 meses da aplicação das fontes de B, verificou diferença entre as fontes apenas na camada mais profunda $(20,0-40,0 \mathrm{~cm})$, onde, constatou maior efeito residual de $B$ proveniente do fertilizante de menor solubilidade (borogran). Mas, aos 48 meses após o plantio, no presente trabalho, esse maior efeito residual da fonte de menor solubilidade (borogran) foi verificado na camada superficial $(0,0$ a $20,0 \mathrm{~cm})$, sendo este um indicativo que o fertilizante mais solúvel (ácido bórico), possivelmente, tenha percolado para camadas mais profundas. Segundo Abreu et al. (2004), as perdas por lixiviação do B proveniente do ácido bórico (alta solubilidade) foram mais rápidas quando comparadas às fontes de menor solubilidade.

A reaplicação de $B$ em cobertura, aplicada na projeção da copa, aos 34 e 46 meses após o plantio, na dose de $1 \mathrm{~kg} \mathrm{ha}^{-1}$ de $\mathrm{B}$ cada, utilizando o fertilizante ácido bórico, proporcionou incremento no teor deste elemento na entre linha de plantio, nas camadas de 0,0 a 20,0 e 20,0 a 40,0 cm. Mesmo com essas reaplicações, de acordo com Raij et al. (1997), os teores ficaram dentro da faixa considerada média para a cultura. Este aumento de B no perfil do solo aproximadamente três vezes maior quando comparado à ausência da reaplicação - foi suficiente para propiciar incremento de $15,3 \%$ na estimativa de volume de madeira com casca e, diante dessa assertiva, é possível que aplicação de $1 \mathrm{~kg} \mathrm{ha}^{-1}$ de $\mathrm{B}$ no sulco de plantio foi 
insuficiente para que a cultura expressasse o seu potencial genético, visto que a reaplicação do elemento foi benéfica para a produtividade da cultura.

Bouchardet (2002) constatou em clones de eucalipto que a aplicação de $1 \mathrm{~kg}^{-1} \mathrm{~h}^{-1}$ de B é suficiente para atender as necessidades da cultura, até os 24 meses de idade. No presente estudo, notou-se que, para o incremento de madeira, foi necessária a reaplicação do elemento, promovendo teores de 0,50 e $0,47 \mathrm{mg} \mathrm{dm}^{-3}$ de $B$ nas camadas de 0,0 a $20,0 \mathrm{~cm}$ e 20,0 a $40,0 \mathrm{~cm}$, respectivamente.

Em relação à concentração de $B$ no folhedo aos 48 meses após o plantio, houve maior concentração de $\mathrm{B}$ oriundo do fertilizante borogran, quando comparado à testemunha; logo, as concentrações de B proveniente da aplicação de ácido bórico, comportaram-se de maneira similar à testemunha (Tabela 6 ).

Tabela 6 - Concentrações de boro no folhedo de eucalipto aos 48 meses após o plantio em função dos tratamentos com boro. Três Lagoas/MS, 2016.

\begin{tabular}{cc}
\hline & Concentração de $\mathbf{B}\left(\mathbf{m g ~ k g}^{-1}\right)$ \\
Tratamentos & \\
\hline Plantio & $43,25 \mathrm{~b}$ \\
Testemunha & $46,25 \mathrm{ab}$ \\
Acido Bórico & $49,58 \mathrm{a}$ \\
Borogran & 4,13 \\
\hline D.M.S. (5\%) & \\
\hline Foliar & $45,72 \mathrm{a}$ \\
Sem & $47,00 \mathrm{a}$ \\
\hline Com & 2,78 \\
\hline D.M.S. (5\%) & $42,77 \mathrm{~b}$ \\
\hline Reaplicação & $47,94 \mathrm{a}$ \\
Sem & 2,78 \\
\hline Com & 8,69 \\
\hline D.M.S. (5\%)
\end{tabular}

Médias seguidas de mesma letra na coluna não diferem pelo teste de Tukey, a $5 \%$ de probabilidade Fonte: CELESTRINO, 2016

Era de se esperar que o fertilizante de baixa solubilidade (borogran) apresentasse maior efeito residual, em virtude de sua liberação gradativa, o que possivelmente favoreceria a acumulação do elemento em folhas senescentes, e, consequentemente, o seu retorno ao solo pelo processo de ciclagem, também conhecido como ciclo biogeoquímico. Contudo, no presente estudo, não ficou evidente a diferença entre as fontes de B, visto observado concentrações semelhantes de $B$ no folhedo. Vale ressaltar que o fertilizante boragran foi superior ao tratamento que não recebeu a aplicação do elemento (testemunha), e este não diferiu do fertilizante ácido bórico.

Vieira et al. (2014) verificaram em povoamento de Eucalyptus urophylla $\times$ Eucalyptus globulus, com 5,5 anos de idade, que a concentração mensal de B na folha da serapilheira foi de $29,97 \mathrm{mg} \mathrm{kg}^{-1}$, sendo o restante das concentrações de B na serapilheira advindo dos galhos grossos, galhos finos e miscelânea. Carvalho et al. (2015) constataram em povoamento clonal de Eucalyptus saligna Smith, aos 4,5 anos de idade, concentração de $24,1 \mathrm{mg} \mathrm{kg}^{-1}$ de B presente na serapilheira. De acordo com Gonçalves et al. (2000), os micronutriente, em geral, 
são acumulados em grande quantidade na serapilheira, devido sua baixa mobilidade dentro da planta. Segundo esses autores, existe uma relação positiva entre idade da folha e concentração dos elementos.

Verificou-se que as reaplicações de B, em cobertura, aos 34 e 46 meses após o plantio, promoveram maior concentração de $B$ no folhedo, quando comparado aos tratamentos que não receberam essa reaplicação. Sendo assim, é possível que as reaplicações de B favoreceram a concentração do elemento na folha; logo, propiciaram efeito benéfico na concentração deste no folhedo e, posteriormente, garantindo maior retorno de $B$ ao solo pelo ciclo biogeoquímico.

\section{CONCLUSÃO}

O efeito residual da aplicação de $1 \mathrm{~kg} \mathrm{ha}^{-1}$ de $\mathrm{B}$, independente da fonte utilizada, não proporcionou acréscimos em produtividade de madeira, quando comparado à testemunha. No entanto, o clone em questão necessitou de duas reaplicações de B ( $1 \mathrm{~kg} \mathrm{ha}^{-1}$ de B cada) para expressar o seu potencial genético, garantindo assim, maior DAP e volume de madeira com casca aos 48 meses após o plantio.

\section{AGRADECIMENTO}

À Fundação de Amparo à Pesquisa do Estado de São Paulo (FAPESP) pelo apoio financeiro da pesquisa (Processo FAPESP: 2014/03387-6) e à Cargill Agrícola S/A.

\section{REFERÊNCIAS BIBLIOGRÁFICAS}

ABREU, C.A; RAIJ, B.V,; ABREU, M.F; GABE, U; YASUDA, M. Reação e movimentação de boro no solo aplicado como ulexita, fritas e ácido bórico. In: Fertbio 2004, Lages. Resumo da Fertbio 2004. Lages: Universidade de Lages, 2004.

ALTHOFF, P., A.C. OLIVEIRA, E.J. MORAIS, S. FONSECA."Eucalypt dieback in "Cerrado" areas in north northwest of Minas Gerais". En: SCHÖNAU, A.P.G. Intensive Forestry: The role of eucalypts. Pretoria. Southern Afr. Inst. For.,p. 598-609.1991

BOUCHARDET, J.A. Crescimento, características físicas e anatômicas da madeira juvenil de dois clones de Eucalyptus grandis Hill ex Maiden em resposta à aplicação de boro. (Dissertação de Mestrado) - Escola Superior de Agricultura Luiz de Queiroz, Universidade de São Paulo, Piracicaba, 2002. 69 p.

BROWN, P.H; BELLALOUI, N.; WIMMER, M.A.; BASSIL, E.S.; RUIZ, J.; HU, H.; PFERFFER, H.; DANNEL, F.; ROMHELD, V. Boron in plant biology. Plant Biol. v. 4, p. 205-223. 2002.

CARVALHO, R. R, V.; ANDRADE, V. H. F.; LENER, J., BASSO, S.; MANFIO, M. M. Estimativa dos micronutrientes na serapilheira acumulada de um povoamento de Eucalyptus saligna (Smith.), São Gabriel-RS. Enciclopédia biosfera, Centro Científico Conhecer - Goiânia, v.11 n.21; p. 976, 2015.

CELESTRINO, T. S. Fontes e modos de aplicação de boro na cultura do eucalipto (clone 1144). 2014. Dissertação (Mestrado em Agronomia/Sistemas de Produção) - Faculdade de Engenharia, Universidade Estadual Paulista, Ilha Solteira, 2014. $56 \mathrm{p}$.

DAHMARDEH, M.; MEHRAVARAN, L.; NADERI, S. Eucalyptus plantlet growth in relation to foliar application with complete fertilizers in Southeast of Iran. Iran, Department of Agronomy, Faculty of Agriculture, University of Zabol. African Journal of Biotechnology, v. 10, p. 14812-14815, 2011. 
FAQUIN, V. Nutrição Mineral de Plantas. Lavras: UFLA/FAEPE, 2005. 183p.

FERREIRA, D. F. SISVAR: um programa para análises e ensino de estatística. Revista Symposium, Lavras, v.6, n.1, p. 36-41, 2008.

FONSECA, S.; MALUF, J. L. P; OLIVEIRA, A. C. Adubação de Eucalyptus camaldulensis com boro e zinco em solos de cerrado na região de Brasilândia-Minas Gerais. In: CONGRESSO FLORESTAL BRASILEIRO, 6., Campos do Jordão. Anais... São Paulo: SBS; SBEF, v. 3, p. 403-406, 1990.

GAZOLA, R. N. Adubação nitrogenada, fosfatada e potássica na cultura do eucalipto (Clone I 144 - E. urograndis). 2014. Dissertação (Mestrado em Agronomia/Sistemas de Produção) - Faculdade de Engenharia, Universidade Estadual Paulista, Ilha Solteira, 2014. 83 p.

GIOVANETTI, R.Z. O uso de boro na Lwarcel Celulose e Papel Ltda. In: SIMPÓSIO SOBRE O USO DO BORO EM FLORESTAS DE EUCALIPTO, 2., Piracicaba. 1998. Anais. Piracicaba: IPEF; ESALQ, p.172-188, 1999.

GONÇALVES, J.L.M.; VALERI, S.V. Eucalipto e Pínus. In: FERREIRA, M.E.; CRUZ, M.C.P.; RAIJ, B.; ABREU, C.A. (Eds) Micronutrientes e elementos tóxicos na agricultura. Jaboticabal, CNPq/FAPESP/POTAFOS, p.393-417. 2001.

LOPES, A. S. Micronutrientes: filosofias de aplicação, fontes, eficiência agronômica e preparo de fertilizantes. In: SIMPÓSIO SOBRE MICRONUTRIENTES NA AGRICULTURA, 1988, Jaboticabal. Anais... Piracicaba, POTAFOS/CNPQ, p. 357-390. 1991.

MAFFEIS, A. R.; SILVEIRA, R. L. V. A.; BRITO, J. O. Reflexos das deficiências de macronutrientes e boro no crescimento de plantas, produção e qualidade de óleo essencial em Eucalyptus citriodora. Scientia Forestalis, Piracicaba, n. 57, p. 87-98, 2000

MARSCHNER, H. Mineral nutritional of higher plants. London: Academic, 1995. 889p

MENEGASSI, A. D. Produção de mudas de eucalipto sob diferentes fontes de adubação. Pato Branco-PR, UTFPR, 2012.

MORTVEDT, J.J. Needs for controlled-availability micronutrient fertilizers. Fertilizer Research, n. 38, p. 213-221, 1994.

OLIVEIRA, S. A; MORAES, M. L. T; BUZETTI, S. Efeito da adubação NPK com e sem boro no crescimento de Eucalyptus citriodora Hook. Revista do Instituto Florestal, São Paulo, v. 13, n. 2, p. 115-120, 2001

PAULA, T.A. Doses, fontes e formas de aplicação de boro em floresta de eucalipto. 2009. $66 \mathrm{f}$. Dissertação (Mestrado em Fitotecnia) - Escola Superior de Agricultura Luiz de Queiroz, Universidade de São Paulo, Piracicaba. 2009.

PINHEIRO, A.L. Reflexos da fertilização mineral de boro na estrutura anatômica, no crescimento e na seca-deponteiro de Eucalyptus citriodora Hook e Eucalyptus camaldulensis Dehn no Cerrado de Minas Gerais. (Tese de Doutorado) - Universidade Federal do Paraná, Curitiba. 1999. 191 p.

RAIJ, B. van.; ANDRADE, J. C.; CANTARELLA, H.; QUAGGIO, J. A. Análise química para avaliação da fertilidade de solos tropicais. Campinas: IAC, 2001. 285 p.

RAIJ, B. van.; CANTARELLA, H.; QUAGGIO, J. A.; FURLANI, A. M. C. Recomendações de adubação e calagem para o estado de São Paulo (Boletim Técnico 100). 2 ed. Campinas: IAC, 1997. 285 p

RAMOS, S. J.; FAQUIN, V.; FERREIRA, R. M. A.; ARAÚJO, J. L.; CARVALHO, J. G. Crescimento e teores de boro em plantas de eucalipto (Eucalyptus citriodora) cultivadas em dois latossolos sob influência de doses de boro e disponibilidade de água. Revista Árvore, Viçosa , v. 33, n. 1, p. 57-65, 2009.

SANTOS, H. G. dos; JACOMINE, P. K. T.; ANJOS, L. H. C. dos; OLIVEIRA, V. A. de; LUMBRERAS, J. F.; COELHO, M. R.; ALMEIDA, J. A. de; CUNHA, T. J. F.; OLIVEIRA, J. B. de. Sistema brasileiro de classificação de solos. 3. ed. rev. e ampl. Brasília, DF: Embrapa, 2013. 353 p. 
SGARBI, F., SILVEIRA, R.L.V.A., TAKAHASHI, E.N., CAMARGO, M.A.F. Crescimento e produção de biomassa de clone de Eucalyptus grandis $x$ Eucalyptus urophylla em condições de deficiência de macronutrientes, B e Zn. Scientia Forestalis, Piracicaba, v.56, p. 69-82,1999.

SILVA, P. H. M. Impactos das doses e do parcelamento da fertilização na produtividade, lixiviação e ciclagem de nutrientes em plantações de eucalipto. 2011. Tese (Doutorado em Ciências/Recursos Florestais) - Escola Superior de Agricultura "Luiz de Queiroz", Universidade de São Paulo, Piracicaba, 2011. 118 p.

TIRLONI, C.; DANIEL, O.; VITORINO, A. C. T; NOVELINO, J. O; CARDUCCI, C. E; HEID, D. M. Crescimento de Corymbia citriodora sob aplicação de boro nas épocas secas e chuvosas no Mato Grosso do Sul, Brasil. Silva Lusitana, Oeiras, v. 19, n 2, p. 185-194, 2011.

VALERI, S. V.; CORRADINI, L. Fertilização em viveiros para produção de mudas de Eucalyptus e Pinnus. In: GONÇALVES, José.Leonardo. de M., BENEDETTI, V. (Ed.). Nutrição e fertilização florestal. Piracicaba: IPEF. p. 167190, 2000.

VIEIRA, M.; SCHUMACHER, M. V.; ARAÚJO, E. F.; CORRÊA, R. S.; CALDEIRA, M. V. W. Deposição de serapilheira e nutrientes em plantio de Eucalyptus urophylla $\times$ E. globulus. Floresta e ambiente, Rio de Janeiro, v.21, n.3, p. 327$338,2014$.

VOLKWEISS, S. J. Fontes e métodos de aplicação. In: Simpósio sobre micronutrientes na agricultura, 1988, Jaboticabal. Anais... Piracicaba, POTAFOS/CNPQ, p. 391-412,1991. 